\title{
Comparative analysis of intracellular and extracellular antibiotic resistance gene abundance in anaerobic membrane bioreactor effluent
}

\author{
Phillip Wang*, Moustapha Harb*, Ali Zarei-Baygi*, Lauren B. Stadler**, and Adam L. \\ Smith*+
}

*Astani Department of Civil and Environmental Engineering, University of Southern California, 3620 S Vermont Ave, Los Angeles, CA 90089, USA

** Department of Civil and Environmental Engineering, Rice University, 6100 Main Street, Houston, TX 77005, USA

${ }^{\dagger}$ Corresponding author (Adam L. Smith)

Phone: +1 213.740.0473

Email: smithada@usc.edu 


\title{
1 Comparative analysis of intracellular and extracellular antibiotic resistance gene abundance in anaerobic membrane bioreactor effluent
}

\author{
Phillip Wang*, Moustapha Harb*, Ali Zarei-Baygi*, Lauren B. Stadler**, and Adam L. \\ Smith*+
}

*Astani Department of Civil and Environmental Engineering, University of Southern California, 3620 S Vermont Ave, Los Angeles, CA 90089, USA

** Department of Civil and Environmental Engineering, Rice University, 6100 Main Street, Houston, TX 77005, USA

${ }^{\dagger}$ Corresponding author (Adam L. Smith)

Phone: +1213.740 .0473$

Abstract: The growing practice of wastewater reuse poses a significant risk to further dissemination of antibiotic resistance due to the abundance of antibiotic resistance bacteria (ARB) and antibiotic resistance genes (ARGs) in wastewater effluents. Anaerobic membrane bioreactors (AnMBRs) are an emerging wastewater treatment technology capable of reducing the total ARGs and ARB load discharged to receiving environments compared to conventional aerobic treatment processes. While size exclusion is effective at retaining $A R B$ and its associated intracellular ARGs, the abundance and fate of extracellular ARGs in an AnMBR effluent have not been examined. This study elucidates the effect of combined antibiotics loading (ampicillin, erythromycin, and sulfamethoxazole) on the abundance of intracellular and extracellular ARGs in an AnMBR effluent over a period of five weeks. Quantification of targeted genes revealed an overall enrichment of intracellular ARGs (iARGs) and depletion of extracellular (exARGs) in response to antibiotics addition, which suggests exARG uptake as a significant mode of horizontal gene transfer in AnMBR effluents. Comparison of the iARG and exARG abundance profiles showed a potential bias for exARG uptake located on 
28 small plasmids compared to large plasmids.

30 Importance: Antibiotic resistance dissemination is facilitated through horizontal gene

31 transfer (HGT) of ARGs. Currently, conjugation is considered to be the dominant

32 mechanism during wastewater treatment. However, recent studies have detected high

33 abundances of exARGs, implying that transformation may play a greater role in

34 dissemination. While previous studies quantified iARGs and exARGs in wastewater

35 treatment facilities, they did not evaluate temporal changes between the two forms.

36 Further, almost no research has differentiated between iARGs and exARGs in anaerobic

37 processes, which are being considered to replace aerobic activated sludge processes.

38 This study specifically investigates the abundance of targeted iARGs and exARGs in

39 AnMBRs in response to antibiotic pressure to quantify potential exchange of ARGs

40 between intracellular and extracellular compartments. Our findings suggest that exARGs

41 located on small plasmids are preferentially taken up by cells under antibiotic pressure

42 compared to large plasmids, which implies heterogenous HGT mechanisms among the

43 plasmid community. 
46 health (Chioro, et al., 2015). Approximately 2 million clinical cases and 23,000 deaths

47 related to antibiotic resistant infections occur annually in the US (Frieden, 2013). Current

48 projections estimate that the yearly worldwide deaths related to antibiotic resistance will

49 reach 10 million by the year 2050 (O'Neil, 2014). While conventional wastewater

50 treatment plants (WWTPs) are effective at managing organics and nutrients, they are not

51 designed or operated to treat emerging contaminants like antibiotic resistance genes

52 (ARGs) and antibiotic resistant bacteria (ARB). With growing awareness of antibiotic

53 resistance, numerous studies have identified WWTPs as hot spots for the propagation of

54 ARGs and ARB (Bouki, et al., 2013, Michael, et al., 2013). Studies on the effluent quality

55 of conventional WWTPs have reported incomplete removal of both ARGs and ARB

56 (McConnell, et al., 2018, Quach-Cu, et al., 2018). Therefore, ARGs and ARB in treated

57 wastewater can continue to proliferate via horizontal gene transfer (HGT) and vertical

58 gene transfer when discharged into receiving environments.

Analyses of sediment microbial communities near outfall sites of WWTPs have

60 detected similar patterns of ARGs and gene classes as those in WWTP effluents (Chu,

61 et al., 2018). While the influence of effluent ARGs on the sediment microbial community

62 is less prominent with increasing distance from effluent outfall sites, the practice of water

63 reuse (e.g., for agricultural irrigation), removes the environmental buffers associated with

64 conventional handling of treated wastewater and results in direct ARGs and ARB loading

65 to receiving soils. Observations of recent studies generally suggest a positive association 
between proliferation of soil ARGs and contact time with treated wastewater (Fahrenfeld,

67 et al., 2013, Han, et al., 2016, Corno, et al., 2019). Therefore, reducing the abundance of antibiotic resistance elements in treated wastewater is critical to limiting the spread of antibiotic resistance in water reuse applications (Pruden, et al., 2013).

Anaerobic membrane bioreactors (AnMBRs) are an emerging wastewater

71 treatment technology that couples anaerobic biological treatment with membrane

72 separation to recover energy, reduce sludge production, and produce a high-quality

73 effluent comparable to activated sludge processes (Smith, et al., 2012). Although low in

74 carbon, AnMBR effluents are rich in nutrients and can be utilized effectively in agricultural

75 reuse scenarios to offset artificial fertilizer needs. Further, the combination of membrane

76 separation with slower microbial growth under anaerobic conditions can theoretically

77 reduce the load of $A R G$ s and $A R B$ in treated wastewater (Le, et al., 2018). However, the

78 fate of $A R G s$ and $A R B$ within AnMBRs remains poorly understood. Previously, we

79 reported the first long-term investigation of eight ARGs, spanning multiple ARG subtypes,

80 in a bench-scale AnMBR under step-wise increases in influent antibiotic concentrations

81 (Zarei-Baygi, et al., 2019). Our results revealed stark differences in the ARG abundance

82 profile of the biomass versus effluent under all conditions tested. The steep reduction in

83 the ARG abundance profile from the biomass to the effluent is likely due to the effective

84 microbial retention by the submerged membranes(Li, et al., 2019). However, size

85 exclusion by membrane pores may not retain extracellular ARGs (exARGs). Moreover, a 86 growing number of studies have reported a high abundance of extracellular DNA (exDNA)

87 in WWTPs and have suggested that the transformation of exARGs might play a larger 
89 Dong, et al., 2019). Therefore, we suspect that the ARG profile in AnMBR effluent may

90 be heavily influenced by exARGs passing through the membrane pores.

Of concern to human health are the many human pathogens known to enter

92 natural competency (e.g., Campylobacter, Haemophilus, Helicobacter, Neisseria,

93 Pseudomonas, Staphylococcus, Streptococcus, Vibrio), with some pathogenic strains

94 having a subset of their clonal population in a state of constitutive competency (e.g.,

95 Neisseria gonorrhea and Helicobacter pylori). While the transformation of exDNA may be

96 limited to smaller plasmids and not be effective at disseminating large multi-drug resistant

97 plasmids, smaller non-conjugative plasmids can also confer multi-drug resistance in

98 bacteria (San Millan, et al., 2009, Lean and Yeo, 2017). Therefore, the direct loading of

99 exARGs, iARGs, and ARB to areas of potential human contact could significantly

100 accelerate the development of antibiotic resistant human pathogens.

Previous studies on exARGs and iARGs have focused on investigating their

102 abundance at multiple environmental locations, such as various types of WWTPs, water

103 sources, and sediments (Mao, et al., 2014, Wang, et al., 2016, Zhang, et al., 2018, Dong,

104 et al., 2019). However, no studies to date have examined the effect of antibiotics addition

105 on exARG and ARG abundance over time. The dynamic relationship between exARGs

106 and iARGs within a microbial community in antibiotic-influenced environments remains

107 an area of much needed investigation. The potential cyclical movement of exDNA 108 between microbial hosts and the extracellular compartment may be a fundamental

109 mechanism for the conservation and propagation of ARGs and ARG associated MGEs

110 between distinct and distant microbial communities. While AnMBRs could theoretically 
111 lessen the load of ARGs and ARB to receiving environments compared to conventional

112 treatment process, the potential propagation of exARGs in the effluent stream needs

113 further research. In this study, we characterized the effect of a combined mixture of

114 antibiotics loading on the antibiotic resistance characteristics of an AnMBR effluent 115 stream.

116 2. Materials and Methods

\subsection{AnMBR Configuration and Monitoring}

A bench-scale AnMBR with a working volume of $5 \mathrm{~L}$ was operated at $25{ }^{\circ} \mathrm{C}$ as

119 previously described (Zarei-Baygi, et al., 2019). Briefly, the AnMBR housed three 120 separate submerged flat-sheet silicon carbide microfiltration membranes $(0.1 \mu \mathrm{m}$ pore 121 size, Cembrane, Denmark), with a total effective membrane area of approximately 0.015

$122 \mathrm{~m}^{2}$. Synthetic wastewater was used to reduce the variable background influence of 123 antibiotics, $A R B$, and $A R G$ s associated with real wastewater. The synthetic wastewater 124 recipe was formulated to represent US domestic wastewater (Supporting Information (SI) 125 Table S1) (Smith, et al., 2013). The AnMBR was seeded with sludge from a mesophilic 126 anaerobic digester at the Joint Water Pollution Control Plant (Carson, CA). AnMBR 127 performance was monitored by measuring water quality parameters including soluble 128 chemical oxygen demand (sCOD), total chemical oxygen demand (tCOD), volatile fatty 129 acids (VFAs), and mixed liquor and volatile suspended solids (MLSS/MLVSS). Biogas 130 production was monitored by an in-line gas flowmeter and assessed for methane content 131 by gas chromatography with flame ionization detection (GC-FID). Steady AnMBR 132 performance was defined as low effluent COD (<50 mg/L), stable biogas production, and 
133 high methane content (>60\%) over a phase of 10 days. After reaching steady AnMBR

134 performance, three antibiotics, sulfamethoxazole (sulfonamide), erythromycin

135 (macrolide), and ampicillin ( $\beta$ - lactam), were added to the influent at $250 \mu \mathrm{g} / \mathrm{L}$ (day 3 ) to

136 represent antibiotic concentrations at the high range of hospital wastewater(Xu, et al.,

137 2016, Kulkarni, et al., 2017). Influent antibiotics concentration was maintained at $250 \mu \mathrm{g} / \mathrm{L}$

138 for the entirety of the antibiotics loading phase (day 3 to day 35). Effluent lines were

139 cleaned with sodium hypochlorite $0.5 \%(\mathrm{v} / \mathrm{v})$ before the start of the experiment.

140 Membrane modules were removed for physical and chemical cleaning $0.5 \%(v / v)$ before

141 the addition of antibiotics.

\subsection{Antibiotic Quantification}

Antibiotic quantification procedures were carried out as previously described

144 (Zarei-Baygi, et al., 2019). Briefly, individual antibiotic concentrations of each sample

145 were analyzed by direct injection liquid chromatography mass spectrometry with

146 electrospray ionization (LC-ESI-MS) on a 6560 Ion Mobility Quadrupole Time-of-Flight

147 (IM-QTOF) LC-MS system (Agilent). Chromatographic separation and ionization were

148 achieved by employing a 1290 Infinity UHPLC with EclipsePlus C18 column (2.1 mm; 50

$149 \mathrm{~mm}$; 1.8um) followed by a Dual Agilent Jet Stream (ASJ) ESI. Standard curves were

150 generated by matrix-matched external calibration of serial dilutions of antibiotics

151 purchased from Sigma (>99\% purity). Practical quantitation limits (PQL) for each target

152 compound were determined to be $<0.1 \mu \mathrm{g} / \mathrm{L}$ based on previously optimized LC-ESI-MS

153 conditions (Zarei-Baygi, et al., 2019). Details on sample preparation, optimized LC

154 program, and MS operational conditions can be found in the (SI Table 3). 


\section{3 qPCR quantification of ARGs}

qPCR reactions were carried out using a LightCycler 96 (Roche, Basel,

157 Switzerland) targeting a set of nine genes. The nine targeted genes included: a class one

158 integrase gene (int/1), a single copy per cell gene (rpoB), and seven ARGs conferring

159 resistance to $\beta$-lactams (oxa-1 and ampC), macrolides (ermF), sulfonamides (sul1 and 160 sul2), and tetracyclines (tetW and tetO). Targeted ARGs were chosen based on their

161 common detection in domestic wastewater studies (Pruden, et al., 2006, Ma, et al., 2011,

162 Munir, et al., 2011). qPCR reactions were done in $20 \mu \mathrm{L}$ reactions with $10 \mu \mathrm{L}$ of qPCR

163 master mix (Forget-Me-Not EvaGreen, Biotium, Fermont, CA), forward and reverse

164 primers at $0.25 \mu \mathrm{M}$ (final concentration) each, $1 \mu \mathrm{L}$ of DNA template, and ddiH2O. Each

165 reaction was performed in triplicate. Details for the thermal cycling conditions for all

166 targeted ARGs are provided in the (SI Table 2). All qPCR results were normalized to

167 effluent sample volume for comparison of ARG abundance across sampling points.

168 Results were represented as total abundance instead of normalized values relative to 169 chromosomal $r p o B$ gene due to previous reports of faster decay rates for chromosomal

170 DNA versus plasmid DNA, which could lead to inflated reports of exARG concentration

171 when normalizing to chromosomal genetic markers (Mao, et al., 2014).

\subsection{Intracellular and extracellular DNA extraction}

iDNA and exDNA extractions were carried out using the same $500 \mathrm{~mL}$ effluent

174 samples for each sampling point. Internal standards to correct for DNA recovery across

175 sample processing were added to each effluent sample by spiking with approximately

$1762 \times 10^{6}$ copies of plasmid pUC19 immediately after collection. Spiked effluent samples 
177 were filtered using vacuum filtration through sterile cellulose acetate membrane filters

178 (0.22um, 45mm diameter, Whatman). Processed filters with collected biomass were used

179 for iDNA extractions. The processed filters were cut into pieces and placed in $2 \mathrm{~mL}$ sterile

180 tubes and mixed with lysis buffer before bead beating with zirconium beads. iDNA

181 extractions were carried out using the Maxwell 16 instrument (Promega) and eluted in

$182100 \mu \mathrm{l}$ of buffer AE. The filtrates were used for exDNA extractions using nucleic acid

183 adsorption particles (NAAP) adapted from Wang et al (Wang, et al., 2016). Briefly,

184 autoclaved $\mathrm{Al}(\mathrm{OH})_{3}$ solutions $(47.8 \%, \mathrm{~V} / \mathrm{V})$ were mixed with $5 \%(\mathrm{~g} / \mathrm{mL})$ silica gel $(60-100$

185 mesh size, Sigma) and dried for 36 hours at $60^{\circ} \mathrm{C}$. Dried silica gels coated with $\mathrm{Al}(\mathrm{OH})_{3}$

186 were then sealed in a cylindrical glass container $(1.5 \times 40 \mathrm{~cm})$ as NAAP columns. The

187 previously mentioned filtrate samples were passed through the NAAP columns. Adsorbed

188 exDNA were eluted from the NAAP columns with $100 \mathrm{~mL}$ of elution buffer $(15 \mathrm{~g} / \mathrm{L} \mathrm{NaCl}$,

$18930 \mathrm{~g} / \mathrm{L}$ tryptone, $15 \mathrm{~g} / \mathrm{L}$ beef extract, $3.75 \mathrm{~g} / \mathrm{L}$ glycine, $0.28 \mathrm{~g} / \mathrm{L} \mathrm{NaOH}, \mathrm{pH}$ of $9.3 \pm 0.2)$.

190 Eluates were then collected and filtered with polyethersulfone filters (0.22 um, Millipore,

191 USA). ExDNA in the filtrates were precipitated using an equal volume of isopropanol,

192 incubated at room temperature for $16 \mathrm{~h}$, and centrifuged at $10,000 \mathrm{~g}$ for $10 \mathrm{~min}$ at room

193 temperature. After decantation of the supernatant, the centrifuged pellets were mixed with

$19470 \%$ ethanol (v/v) and centrifuged again at $10,000 \mathrm{~g}$ for $5 \mathrm{~min}$ at room temperature. After

195 a second decantation, the residual ethanol was evaporated in a $60^{\circ} \mathrm{C}$ oven and the pellets

196 were re-suspended in $4 \mathrm{~mL}$ of sterilized TE buffer. Extracted DNA samples were

197 quantified using Quant-iT PicoGreen (Thermo Fisher) and a BioSpectrometer

198 (Eppendorf, Hamburg, Germany). iDNA extraction efficiency was carried out without the 199 use of an iDNA internal standard due to the consistent performance of the Maxwell 16 
200 instrument (Promega) (data not shown). Extraction efficiency of each exDNA extraction

201 was assessed using spiked pUC19 serving as the exDNA standard (SI Table 2). The

202 qPCR results for each exARG data point were adjusted based on the corresponding

203 extraction efficiency of the exDNA standard (e.g,, gene copies of exampC/(gene copies

204 of pUC19/total spiked gene copies of pUC19)). All DNA extracts were stored at $-80{ }^{\circ} \mathrm{C}$ 205 until analysis.

\subsection{Statistical Analysis Methods}

Statistical analyses were performed using MaxStat Lite 3.6. Significant changes in

208 ARG abundance at different time points were assessed using a 2-tailed unpaired

209 student's t-test. Pearson and Spearman rank correlations were used to assess

210 correlations between data points over a 95\% confidence interval. Strength of correlations

211 were identified based on the Pearson coefficient $r$, as $r>0.7$ or $r<-0.7$ for strong

212 correlations, $-0.7<r<-0.5$ or $0.5<r<0.7$ for moderate correlations, and $-0.5<r<-0.3$ or

$2130.3<r<0.5$ for weak correlations. Pearson correlations were performed on separated

214 iARG and exARG data sets. Spearman rank correlations were performed on the

215 combined $\mathrm{A} A \mathrm{RG}$ and exARG data sets due to the dynamic nature of gene transport, 216 synthesis, and degradation.

Total bacteria and ARB in the effluent were enumerated using the heterotrophic

219 plate count method with nutrient agar as the media (Federation, 2005). Ampicillin (AMP), 220 tetracycline (TET), erythromycin (ERY), and sulfamethoxazole (SMX) resistant bacteria 
221 counts were determined by growth on nutrient agar plates supplemented with

222 corresponding AMP, TET, SMX, or ERY. TET resistance bacteria counts were included

223 as a control given the lack of tetracycline in the synthetic wastewater. Final concentration

224 for each antibiotic was guided by MIC reports in previous studies: AMP, $16 \mu \mathrm{g} / \mathrm{mL}$; TET,

$22516 \mu \mathrm{g} / \mathrm{mL}$; ERY, $50.4 \mu \mathrm{g} / \mathrm{mL}$; and SMX, $18.1 \mu \mathrm{g} / \mathrm{mL}($ Pei, et al., 2006, Zheng, et al., 2017$)$.

226 All plates were incubated at $35^{\circ} \mathrm{C}$ for $48 \mathrm{hrs}$.

Effluent COD averaged $45.4 \pm 10.7 \mathrm{mg} / \mathrm{L}$, equating to a COD removal of $90.0 \pm$

234 perturbation to the reactor performance (SI Fig1), except for day 17 which saw a slight decrease in biogas production. These results are consistent with previous studies which

236 have shown that this range of antibiotic loading on anaerobic reactors is well below the

237 threshold that would cause a disruption in system performance (Aydin, et al., 2015, Xiong,

238 et al., 2017). Antibiotic removal was relatively stable across the operational phase, with

239 AMP removal ranging from $89-98 \%$, followed by SMX at $69-78 \%$, and ERY at $40-58 \%$

240 (Fig 1). The wide-ranging specific removal rates of these antibiotics in the AnMBR are

241 consistent with those observed for other mainstream anaerobic wastewater treatment 
242 systems, which can vary greatly in comparison to conventional aerobic treatment

243 schemes (Harb, et al., 2019).

Overall, SMX resistance showed the greatest degree of proliferation among the

246 types of antibiotic resistance tested. SMX resistant bacteria in the effluent increased by >

$2473 \log (\mathrm{CFU} / \mathrm{mL})(\mathrm{p}=0.032)$ over the course of the experiment, with the number of total

248 bacteria increasing by $0.68 \log (\mathrm{CFU} / \mathrm{mL})(p=0.027)$ over the same duration (Fig 2). The

249 ratio of SMX resistant bacteria to total bacteria exhibited a non-linear rise from $55.5 \%$

250 (day 1) to $96.5 \%$ (day 57). In comparison, the ratio of AMP resistant bacteria to total

251 bacteria rose from $68.7 \%$ to $75.4 \%$ and the ratio of ERY resistant bacteria to total bacteria

252 fell from $89.3 \%$ to $76.7 \%$. As expected, (given no addition of TET in the influent) counts

253 for TET resistant bacteria frequently fell below the limit of detection (LOD=10 CFU/mL).

254 Among the ARB types tested, only SMX resistant bacteria showed a positive association

255 between the increase in effluent abundance and antibiotic dosing. Our findings were

256 consistent with our previous report and Le et al., where sulfamethoxazole was found to

257 be one of three antibiotics to increase with its corresponding ARB among 19 targeted

258 antibiotics in an MBR system (Le, et al., 2018, Zarei-Baygi, et al., 2019). It is important to

259 note that heterotrophic plate counts only capture a small fraction of microbial diversity.

260 Further, aerobic plating of effluents from anaerobic systems favors quantification of

261 facultative microorganisms and excludes detection of obligate anaerobes. Despite these

262 methodological limitations, HPC used in this capacity still provides useful data regarding 
263 relative changes in $A R B$, which complements our parallel use of culture-independent

264 methods (i.e., qPCR).

265

266

3.3 Total iARGs and exARGs Showed Varied Response Towards Antibiotics

267

Addition

Total iARGs were consistently more abundant than total exARGs by at least 2 log

269 (Gene Copies $/ \mathrm{mL}$ ) throughout the experimental period (Fig 3). Similar findings of higher

270 iARG versus exARG abundance have been reported in most aquatic environments

271 examined (Nielsen, et al., 2007, Mao, et al., 2014, Zhang, et al., 2018, Hao, et al., 2019).

272 In contrast, studies on sediment samples frequently report higher abundance of exARGs

273 than iARGs (Mao, et al., 2014, Dong, et al., 2019). The higher abundance of exARGs

274 versus iARGs in sediment samples is likely due to the adsorption of exDNA to soil colloids,

275 clay particles, and organic matter that can decrease the susceptibility of exDNA

276 degradation from nuclease attacks (Crecchio and Stotzky, 1998, Demanèche, et al., 277 2001).

The addition of antibiotics in the influent coincided with increasing abundance of

279 total iARGs in AnMBR effluent, rising from 5.52 (day 1) to 7.13 (day 35) log (Gene

280 Copies $/ \mathrm{ml}$ ). The observed increase in total iARGs during the antibiotics loading phase is

281 likely due to the selection for ARB and their associated ARGs in the effluent stream. The

282 abundance of total exARGs, over the same time frame, exhibited a non-linear decrease

283 from 3.46 (day 1) to 3.16 (day 35). Interestingly, total exARGs showed an initial rise to

$2844.2 \log$ (gene copeies/mL) (day 21) followed by a precipitous drop to $2.11 \log$ (Gene 
285 Copies $/ \mathrm{ml}$ ) midway through the experimental run (day 28). The initial increase in total exARGs before day 28 could be due to antibiotic induced exDNA release for the purpose of biofilm formation and HGT (Zafra, et al., 2012, Okshevsky and Meyer, 2015, Sugimoto, et al., 2018). Moreover, antibiotics, biofilm formation, and exDNA are all associated with the induction of natural competency of many bacterial species (Li, et al., 2001, Ibanez de Aldecoa, et al., 2017). Therefore, an increase in competent microbial members within the effluent stream could explain the sharp decrease in total exARGs abundance on day 28. In the post-antibiotics loading phase, the increase in total exARGs is likely due to the loss of ARG-associated MGEs as the fitness advantage of retaining ARG-associated MGEs decreases. However, the persistence of MGEs in microbial hosts under antibiotic-free conditions is influenced by the surrounding genes. While low copy large plasmids typically encode for additional maintenance genes (e.g., partitioning and toxin-antitoxin systems)

297 that promote their own survival in the absence of antibiotic pressure (Ghaly and Gillings, 2018), high copy small plasmids do not encode for these maintenance genes and are generally more easily lost in the absence of strong selective pressure.

\subsection{Mixed-Antibiotics Loading Increases the Abundance of Effluent iARGs}

302 the effluent, followed by sul1, rpoB, sul2, tetO, tetW, ermF, oxa-1, and ampC (Fig 4).

303 During the antibiotics loading phase, the abundance of sul2 exhibited the highest 304 increase, rising from 4.57 to 7.08 log (Gene Copies/ml) $(p<0.01)$. The abundance of sul1 305 and int/1 increased from 5.9 to $6.56 \log ($ Gene Copies/ml) $(p=0.168)$ and from 5.46 to 6.21 $306 \log ($ Gene Copies $/ \mathrm{ml})(p=0.238)$, respectively. The relatively high abundance of sul1, sul2, 
307 and int/1 among targeted ARGs in our study is consistent with previous reports (Rowe, et

308 al., 2016, Xu, et al., 2016, Zarei-Baygi, et al., 2019). Interestingly, the abundance of oxa-

3091 rose from 2.39 to $3.58 \log ($ Gene Copies $/ \mathrm{ml})(p<0.01)$, while the abundance of ampC

310 decreased from 1.16 to $0.9 \log ($ Gene Copies $/ \mathrm{ml})(p=0.02)$. The preferential selection of

311 oxa-1 over ampC could be due to the co-localization of oxa-1 and sul2 on the same MGE,

312 which would allow for the co-selection of oxa-1 from the SMX addition. This hypothesis is

313 supported by the strong correlation between sul2 and oxa-1 $(r=0.772)(p<0.01)$ and the

314 low AMP $(2.8 \mu \mathrm{g} / \mathrm{L}$ to $22.45 \mu \mathrm{g} / \mathrm{L})$ selective pressure in the effluent. Despite high ERY 315 concentrations $(107.0 \mu \mathrm{g} / \mathrm{L}$ to $130.5 \mu \mathrm{g} / \mathrm{L})$ in the effluent, ermF abundance showed 316 modest increase from 2.91 to $3.86 \log ($ Gene Copies/ml) $(p<0.01)$. Copies $/ \mathrm{ml}) \quad(p<0.01)$. Consistent with our previous co-localization hypothesis, the 319 abundance of oxa-1 showed a similar sharp decrease, dropping from 3.5 to 2.08 log 320 (Gene Copies/ml) ( $p<0.01)$. Additional iARG decreases included ermF, tetO, and tetW, 321 which declined in abundance from 3.68 to $2.72 \log ($ Gene Copies $/ \mathrm{ml})(p<0.01), 3.27$ to 322 2.31 log (Gene Copies/ml) ( $p<0.01)$, and 3.67 to $2.86 \log ($ Gene Copies/ml) $(p<0.01)$, 323 respectively. Surprisingly, the abundance of sul1 and int/1 remained elevated at 6.59 and $3247.19 \log ($ Gene Copies/ml), respectively. The elevated concentrations of sul1 and int/1 325 genes in the post antibiotics phase may be due to the greater persistence of low copy 326 number large plasmids compared to high copy small plasmids in microbial hosts (Carroll 327 and Wong, 2018). On a population level, non-conjugative plasmids tend to be smaller in 328 size and are present in higher copy numbers (up to 200 copies per cell) compared to 329 conjugative plasmids, which tend to be much larger in size and present in lower copy 
330 numbers (<10 copies per cell) (Watve, et al., 2010, Shintani, et al., 2015). Under selective

331 pressure, high copy number plasmids could theoretically increase in abundance within a

332 microbial community more rapidly than low copy plasmids. However, small non-

333 conjugative plasmids typically do not encode for maintenance or stability genes and are

334 easily lost when the selective pressure is removed. In contrast, low copy conjugative

335 plasmids may exhibit longer persistence within a microbial community due to additional

336 maintenance systems encoded on the plasmid backbone (e.g., partitioning and toxi-

337 antitoxin systems) (Garcillan-Barcia, et al., 2011). Overall, sul1 and sul2 were the two

338 most abundant ARGs detected and sul2 exhibited the greatest increase under antibiotic

339 pressure. Further, the sharp rise of sul2 in response to antibiotic stress and the

340 persistence of sul1 in the post-antibiotics phase is consistent with the SMX resistant

341 bacteria proliferation observed in our HPC results.

343 between two sets of genes, sul2, oxa-1, and tetO $(r>0.65, p<0.05)$ and ermF, sul1, and

344 int/1 $(r>0.6, p<0.05)$, which suggests the presence of multi-drug resistant plasmids

345 and/or distinct modes of plasmid propagation rates (e.g., low versus high copy plasmid).

346 Moreover, sul1 was strongly correlated with intl1 $(r=0.869, p<0.01)$, while no correlation

347 was found between sul2 and int/1 ( $r=-0.059, p=0.853)$, which suggests that the

348 discrepant response of sul1 and sul2 to the addition of antibiotics was attributed to the

349 different types of MGEs surrounding sul1 and sul2. Consistent with this explanation,

350 previous studies examining the characteristics of isolated plasmids harboring sul1 and

351 sul2 commonly detected sul2 on small non-conjugative plasmids whereas sul1 was

352 exclusively found on large conjugative plasmids (Enne, et al., 2004, Antunes, et al., 2005, 
353 San Millan, et al., 2009, Wu, et al., 2010, Dominguez, et al., 2019). The strong correlation

354 between ermF with sul1 and int/1 suggest that ermF is either co-localized with sul1 and

355 int/1 or located on similar low copy number conjugative plasmids, which could explain the

356 modest increase in abundance for sul1, int1, and ermF despite significant concentrations

357 of SMX $(54.9 \mu \mathrm{g} / \mathrm{L}$ to $75.2 \mu \mathrm{g} / \mathrm{L})$ and ERY $(107.0 \mu \mathrm{g} / \mathrm{L}$ to $130.5 \mu \mathrm{g} / \mathrm{L})$ in the effluent stream.

3.5 Temporal Abundance Prolife of Effluent exARGs and iARGs Revealed

Distinct Patterns

In the pre-antibiotics phase, all exARGs were detected, ranging from 0.25 to 3.1

$\log$ (Gene Copies/ml) (Fig 5). Interestingly, the addition of antibiotics coincided with an

overall decrease in exARG abundance, which contrasted the enrichment of iARGs during the same period. Similar to iARGs, exARGs are likely associated with MGEs of varied sizes. The uptake of exDNA by microbial hosts has been documented to favor small plasmids and DNA fragments, which could cause the overall variability of exARG abundance (Prudhomme, et al., 2006, Slager, et al., 2014). Therefore, the size of the genetic carrier harboring exARG would influence its rate of degradation and uptake by microbial hosts. removal, which supports the hypothesis of size dependent exDNA uptake. Similar to the

371 Pearson correlation analysis for iARGs, extracellular sul1 was strongly correlated with

372 extracellular int/1 $(r=0.87, p<0.01)$. Interestingly, extracellular sul2 was strongly

373 correlated with extracellular int/1 as well $(r=0.78 p<0.01)$ and was moderately correlated 374 with extracellular sul1 $(r=.59 \mathrm{p}<0.01)$. While some studies have identified sul2 to be 
375 distinctly separate from sul1 and int/1, a few reports have detected sul2 genes on large 376 conjugative plasmids along with sul1 and int/1 genes (Phuong Hoa, et al., 2008, Wu, et

377 al., 2010, Wu, et al., 2010). The positive correlation of extracellular sul1, sul2, and int/1 in

378 the extracellular compartment could be due to the lower uptake efficiency of large 379 plasmids compared to small plasmids. Since sul2 has been documented on both large 380 and small plasmids, there could be a preferential uptake of small sul2-associated 381 plasmids while leaving behind larger sul2-associated plasmids. From the iARG profile, 382 intracellular ermF, sul1, and int/1 all exhibited propagation patterns resembling those of 383 low copy number conjugative plasmids, which are generally larger than non-conjugative 384 plasmids (Garcillan-Barcia, et al., 2011). Since exARGs are simply the cell-free form of 385 iARGs, the greater persistence of extracellular ermF, sul1 and int/1 over extracellular sul2, oxa-1, and tetO could be due to the lower uptake efficiency of larger plasmids compared

387 to smaller plasmids. exARG data sets to further asses the temporal relationship between iARGs and exARGs. Among the ARGs examined, only extracellular sul2 and extracellular tetW were negatively

391 correlated to intracellular sul2 $(r=-0.68, p<0.01)$ and intracellular tetW $(r=-0.836, p$ $<0.01)$, respectively. The negative correlation between extracellular sul2 and intracellular sul2 is consistent with our hypothesis that exARGs can be taken up and enriched within 394 microbial hosts. The lack of a significant correlation among the remaining exARGs and 395 their intracellular counterpart could be due to additional barriers involved in acquiring and 396 maintaining exogenous genes. As stated previously, the uptake of exDNA by microbial 397 hosts would likely favor small plasmids and DNA fragments Further, the maintenance of 
exogenous genes, including ARGs, on linear DNA fragments would require recirculation or integration into the microbial host genome through homologous recombination or transposable elements. In general, non-integrated or circularized fragments would likely

401 be degraded for metabolic purposes or released back into the environment. Therefore, 402 the uptake of exDNA could be the first step in acquiring new functional traits and the 403 quality and compatibility of the genetic carrier adds further selection to the maintenance 404 of the acquired genes. Our findings add support to the hypothesis that the extracellular 405 compartment within microbial communities can serve as a reservoir for genetic resources, 406 including ARGs, with potential uptake biases toward small plasmids or DNA fragments.

While in vitro studies attempting to induce natural competency for many bacterial species have shown limited success, the complexities of environmental conditions are difficult to recreate in controlled laboratory conditions. Further, the induction of natural 410 competency for some bacterial strains have been shown to rely on the production of 411 signaling molecules from other bacterial species (Zhu, et al., 2011). In the context of 412 wastewater reuse, treated wastewater could provide high concentrations of exARGs, 413 environmental stressors, and signaling molecules from highly complex microbial

414 communities that could promote a feedback loop for exDNA release, biofilm formation, 415 and natural competency in the receiving microbial community. This cyclical uptake and 416 release of exARGs, particularly in plasmid form, could increase the total abundance of 417 exARGs within the extracellular matrix due to multiple replication cycles of plasmids within 418 microbial hosts. Additional studies are needed to unravel the complex dynamics between 419 exARG uptake and release within receiving environments such as soil microbial 420 communities. 
In this study, we have shown that under mixed-antibiotics loading (SMX, ERY, and

422 AMP at $250 \mu \mathrm{g} / \mathrm{L})$, SMX resistant bacteria increase from $55.5 \%$ to $96.5 \%$ of total

423 culturable bacteria in the effluent. Complimentary qPCR analysis of iARG abundance

424 revealed a stark increase in sul2 and the persistence of sul1 abundance, which is

425 consistent with our observation of the dominance of SMX resistant bacteria in HPC

426 results. Finally, qPCR analysis of the exARG abundance over the same duration revealed

427 an inverse trend for most exARGs and their intracellular counterparts. Most notably,

428 extracellular sul2 was negatively correlated to intracellular sul2 $(r=-0.68, p=0.001)$, which

429 suggests that competent cells can acquire antibiotic resistance from exARGs. However,

430 it is important to note that qPCR assays are limited to the quantification of pre-determined

431 genes. Further, the correlations drawn in this paper would benefit from experiments

432 directly tracking the movements of iARGs and exARGs. Future studies should use

433 metagenomic guided qPCR analysis to analyze ARGs pertinent to their research

434 question(s) along with their associated MGEs. 
Antunes, P., Machado, J., Sousa, J.C., and Peixe, L. (2005) Dissemination of sulfonamide resistance genes (sul1, sul2, and sul3) in Portuguese Salmonella enterica strains and relation with integrons, Antimicrob Agents Chemother 49: 836-839. Aydin, S., Ince, B., Cetecioglu, Z., Arikan, O., Ozbayram, E.G., Shahi, A., and Ince, O. (2015) Combined effect of erythromycin, tetracycline and sulfamethoxazole on performance of anaerobic sequencing batch reactors, Bioresource technology 186: 207214.

Bouki, C., Venieri, D., and Diamadopoulos, E. (2013) Detection and fate of antibiotic resistant bacteria in wastewater treatment plants: a review, Ecotoxicol Environ Saf 91: 19.

Carroll, A.C., and Wong, A. (2018) Plasmid persistence: costs, benefits, and the plasmid paradox, Canadian Journal of Microbiology 64: 293-304.

Chen, S., and Smith, A.L. (2018) Methane-driven microbial fuel cells recover energy and mitigate dissolved methane emissions from anaerobic effluents, Environmental Science: Water Research \& Technology 4: 67-79. Chioro, A., Coll-Seck, A.M., Hoie, B., Moeloek, N., Motsoaledi, A., Rajatanavin, R., and Touraine, M. (2015) Antimicrobial resistance: a priority for global health action, Bull World Health Organ 93: 439.

Chu, B.T.T., Petrovich, M.L., Chaudhary, A., Wright, D., Murphy, B., Wells, G., and Poretsky, R. (2018) Metagenomics Reveals the Impact of Wastewater Treatment Plants on the Dispersal of Microorganisms and Genes in Aquatic Sediments, Applied and Environmental Microbiology 84: e02168-02117. Effluents of wastewater treatment plants promote the rapid stabilization of the antibiotic resistome in receiving freshwater bodies, Water Res 158: 72-81. Crecchio, C., and Stotzky, G. (1998) Binding of DNA on humic acids: Effect on transformation of Bacillus subtilis and resistance to DNase, Soil Biology and Biochemistry 30: 1061-1067.

Demanèche, S., Jocteur-Monrozier, L., Quiquampoix, H., and Simonet, P. (2001) Evaluation of biological and physical protection against nuclease degradation of claybound plasmid DNA, Applied and environmental microbiology 67: 293-299.

Dominguez, M., Miranda, C.D., Fuentes, O., de la Fuente, M., Godoy, F.A., Bello-Toledo, H., and Gonzalez-Rocha, G. (2019) Occurrence of Transferable Integrons and sul and dfr Genes Among Sulfonamide-and/or Trimethoprim-Resistant Bacteria Isolated From Chilean Salmonid Farms, Front Microbiol 10: 748. Dong, P., Wang, H., Fang, T., Wang, Y., and Ye, Q. (2019) Assessment of extracellular antibiotic resistance genes (eARGs) in typical environmental samples and the transforming ability of eARG, Environment International 125: 90-96.

483

484

485 Enne, V., M Bennett, P., Livermore, D., and Hall, L. (2004) Enhancement of host fitness by the sul2-coding plasmid p9123 in the absence of selective pressure, 958-963. Microbiol 4: 130. 
487 Federation, W.E.a.A. (2005) Standard methods for the examination of water and 488 wastewater, APHA.

489 Frieden, T. (2013) Antibiotic Resistance Threats in the United States, 2013, Brochure US Centrs for Disease Control and Prevention.

Garcillan-Barcia, M.P., Alvarado, A., and de la Cruz, F. (2011) Identification of bacterial plasmids based on mobility and plasmid population biology, FEMS Microbiol Rev 35: 936956. Ghaly, T.M., and Gillings, M.R. (2018) Mobile DNAs as Ecologically and Evolutionarily Independent Units of Life. Impacts of reclaimed water irrigation on soil antibiotic resistome in urban parks of Victoria, Australia, Environ Pollut 211: 48-57. Hao, H., Shi, D.-y., Yang, D., Yang, Z.-w., Qiu, Z.-g., Liu, W.-I., et al. (2019) Profiling of intracellular and extracellular antibiotic resistance genes in tap water, Journal of Hazardous Materials 365: 340-345. micropollutants in mainstream anaerobic wastewater treatment, Curr Opin Biotechnol 57: 94-100.

Ibanez de Aldecoa, A.L., Zafra, O., and Gonzalez-Pastor, J.E. (2017) Mechanisms and Regulation of Extracellular DNA Release and Its Biological Roles in Microbial Communities, Front Microbiol 8: 1390. Kulkarni, P., Olson, N.D., Raspanti, G.A., Rosenberg Goldstein, R.E., Gibbs, S.G., Sapkota, A., and Sapkota, A.R. (2017) Antibiotic Concentrations Decrease during Wastewater Treatment but Persist at Low Levels in Reclaimed Water, Int J Environ Res Public Health 14: 668.

512 Le, T.H., Ng, C., Tran, N.H., Chen, H., and Gin, K.Y.H. (2018) Removal of antibiotic residues, antibiotic resistant bacteria and antibiotic resistance genes in municipal wastewater by membrane bioreactor systems, Water Research 145: 498-508. Pathogen, Acinetobacter baumannii: Good, Bad, Who Knows?, Frontiers in Microbiology 8: 1547.

Li, B., Qiu, Y., Li, J., Liang, P., and Huang, X. (2019) Removal of antibiotic resistance genes in four full-scale membrane bioreactors, Sci Total Environ 653: 112-119. Li, Y.H., Lau, P.C., Lee, J.H., Ellen, R.P., and Cvitkovitch, D.G. (2001) Natural genetic transformation of Streptococcus mutans growing in biofilms, J Bacteriol 183: 897-908. Ma, Y., Wilson, C.A., Novak, J.T., Riffat, R., Aynur, S., Murthy, S., and Pruden, A. (2011) Effect of Various Sludge Digestion Conditions on Sulfonamide, Macrolide, and Tetracycline Resistance Genes and Class I Integrons, Environmental Science \& Technology 45: 7855-7861.

Mao, D., Luo, Y., Mathieu, J., Wang, Q., Feng, L., Mu, Q., et al. (2014) Persistence of extracellular DNA in river sediment facilitates antibiotic resistance gene propagation, Environmental Science and Technology 48: 71-78.

530 Tong, A. (2018) Removal of antibiotic resistance genes in two tertiary level municipal wastewater treatment plants, Sci Total Environ 643: 292-300. 
532 Michael, I., Rizzo, L., McArdell, C.S., Manaia, C.M., Merlin, C., Schwartz, T., et al. (2013)

533 Urban wastewater treatment plants as hotspots for the release of antibiotics in the 534 environment: A review. Water Research. 957-995. Munir, M., Wong, K., and Xagoraraki, I. (2011) Release of antibiotic resistant bacteria and genes in the effluent and biosolids of five wastewater utilities in Michigan, Water research 45: 681-693.

538 Nielsen, K.M., Johnsen, P.J., Bensasson, D., and Daffonchio, D. (2007) Release and persistence of extracellular DNA in the environment, Environmental Biosafety Research 6: 37-53.

Okshevsky, M., and Meyer, R.L. (2015) The role of extracellular DNA in the establishment, maintenance and perpetuation of bacterial biofilms, Crit Rev Microbiol 41: 341-352. O'Neil, J. (2014) AMR Review Paper - Tackling a crisis for the health and wealth of nations.

Pei, R., Kim, S.C., Carlson, K.H., and Pruden, A. (2006) Effect of river landscape on the sediment concentrations of antibiotics and corresponding antibiotic resistance genes (ARG), Water Res 40: 2427-2435. Phuong Hoa, P.T., Nonaka, L., Hung Viet, P., and Suzuki, S. (2008) Detection of the sul1, sul2, and sul3 genes in sulfonamide-resistant bacteria from wastewater and shrimp ponds of north Vietnam, Sci Total Environ 405: 377-384. Pruden, A., Larsson, D.G.J., Amézquita, A., Collignon, P., Brandt, K.K., Graham, D.W., et al. (2013) Management options for reducing the release of antibiotics and antibiotic resistance genes to the environment, Environmental health perspectives 121: 878-885. Pruden, A., Pei, R., Storteboom, H., and Carlson, K.H. (2006) Antibiotic Resistance Genes as Emerging Contaminants: Studies in Northern Colorado, Environmental Science \& Technology 40: 7445-7450.

558 Prudhomme, M., Attaiech, L., Sanchez, G., Martin, B., and Claverys, J.-P. (2006) Antibiotic Stress Induces Genetic Transformability in the Human Pathogen Streptococcus pneumoniae, Science 313: 89. A.R. (2018) The Effect of Primary, Secondary, and Tertiary Wastewater Treatment Processes on Antibiotic Resistance Gene (ARG) Concentrations in Solid and Dissolved Wastewater Fractions, Water 10: 37. Rowe, W., Verner-Jeffreys, D.W., Baker-Austin, C., Ryan, J.J., Maskell, D.J., and Pearce, G.P. (2016) Comparative metagenomics reveals a diverse range of antimicrobial resistance genes in effluents entering a river catchment, Water Sci Technol 73: 15411549. (2009) Multiresistance in Pasteurella multocida is Mediated by Coexistence of Small Plasmids, Antimicrobial Agents and Chemotherapy 53: 3399.

577 Shintani, M., Sanchez, Z.K., and Kimbara, K. (2015) Genomics of microbial plasmids: classification and identification based on replication and transfer systems and host taxonomy, Frontiers in microbiology 6: 242-242.

Slager, J., Kjos, M., Attaiech, L., and Veening, J.W. (2014) Antibiotic-induced replication stress triggers bacterial competence by increasing gene dosage near the origin, Cell 157: 395-406. 
578

Smith, A.L., Skerlos, S.J., and Raskin, L. (2013) Psychrophilic anaerobic membrane bioreactor treatment of domestic wastewater, Water Research 47: 1655-1665.

Smith, A.L., Stadler, L.B., Love, N.G., Skerlos, S.J., and Raskin, L. (2012) Perspectives on anaerobic membrane bioreactor treatment of domestic wastewater: a critical review, Bioresource Technology 122: 149-159.

Sugimoto, S., Sato, F., Miyakawa, R., Chiba, A., Onodera, S., Hori, S., and Mizunoe, Y. (2018) Broad impact of extracellular DNA on biofilm formation by clinically isolated Methicillin-resistant and -sensitive strains of Staphylococcus aureus, Scientific Reports 8: 2254.

Wang, D.N., Liu, L., Qiu, Z.G., Shen, Z.Q., Guo, X., Yang, D., et al. (2016) A new adsorption-elution technique for the concentration of aquatic extracellular antibiotic resistance genes from large volumes of water, Water Res 92: 188-198.

Watve, M.M., Dahanukar, N., and Watve, M.G. (2010) Sociobiological Control of Plasmid Copy Number in Bacteria, PLOS ONE 5: e9328.

Wu, S., Dalsgaard, A., Hammerum, A.M., Porsbo, L.J., and Jensen, L.B. (2010) Prevalence and characterization of plasmids carrying sulfonamide resistance genes among Escherichia coli from pigs, pig carcasses and human, Acta veterinaria Scandinavica 52: 47-47.

Wu, S., Dalsgaard, A., Hammerum, A.M., Porsbo, L.J., and Jensen, L.B. (2010) Prevalence and characterization of plasmids carrying sulfonamide resistance genes among Escherichia coli from pigs, pig carcasses and human, Acta Vet Scand 52: 47. Xiong, Y., Harb, M., and Hong, P.Y. (2017) Performance and microbial community variations of anaerobic digesters under increasing tetracycline concentrations, Applied Microbial Biotechnology 101: 5505-5517.

Xu, Y., Guo, C., Luo, Y., Lv, J., Zhang, Y., Lin, H., et al. (2016) Occurrence and distribution of antibiotics, antibiotic resistance genes in the urban rivers in Beijing, China, Environmental Pollution 213: 833-840.

Zafra, O., Lamprecht-Grandío, M., de Figueras, C.G., and González-Pastor, J.E. (2012) Extracellular DNA Release by Undomesticated Bacillus subtilis Is Regulated by Early Competence, PLOS ONE 7: e48716.

Zarei-Baygi, A., Harb, M., Wang, P., Stadler, L.B., and Smith, A.L. (2019) Evaluating Antibiotic Resistance Gene Correlations with Antibiotic Exposure Conditions in Anaerobic Membrane Bioreactors, Environmental Science \& Technology 53: 3599-3609.

Zhang, Y., Li, A., Dai, T., Li, F., Xie, H., Chen, L., and Wen, D. (2018) Cell-free DNA: A Neglected Source for Antibiotic Resistance Genes Spreading from WWTPs, Environmental Science and Technology 52: 248-257.

Zheng, J., Su, C., Zhou, J., Xu, L., Qian, Y., and Chen, H. (2017) Effects and mechanisms of ultraviolet, chlorination, and ozone disinfection on antibiotic resistance genes in secondary effluents of municipal wastewater treatment plants, Chemical Engineering Journal 317: 309-316.

Zhu, L., Zhang, Y., Fan, J., Herzberg, M.C., and Kreth, J. (2011) Characterization of competence and biofilm development of a Streptococcus sanguinis endocarditis isolate, Mol Oral Microbiol 26: 117-126. 


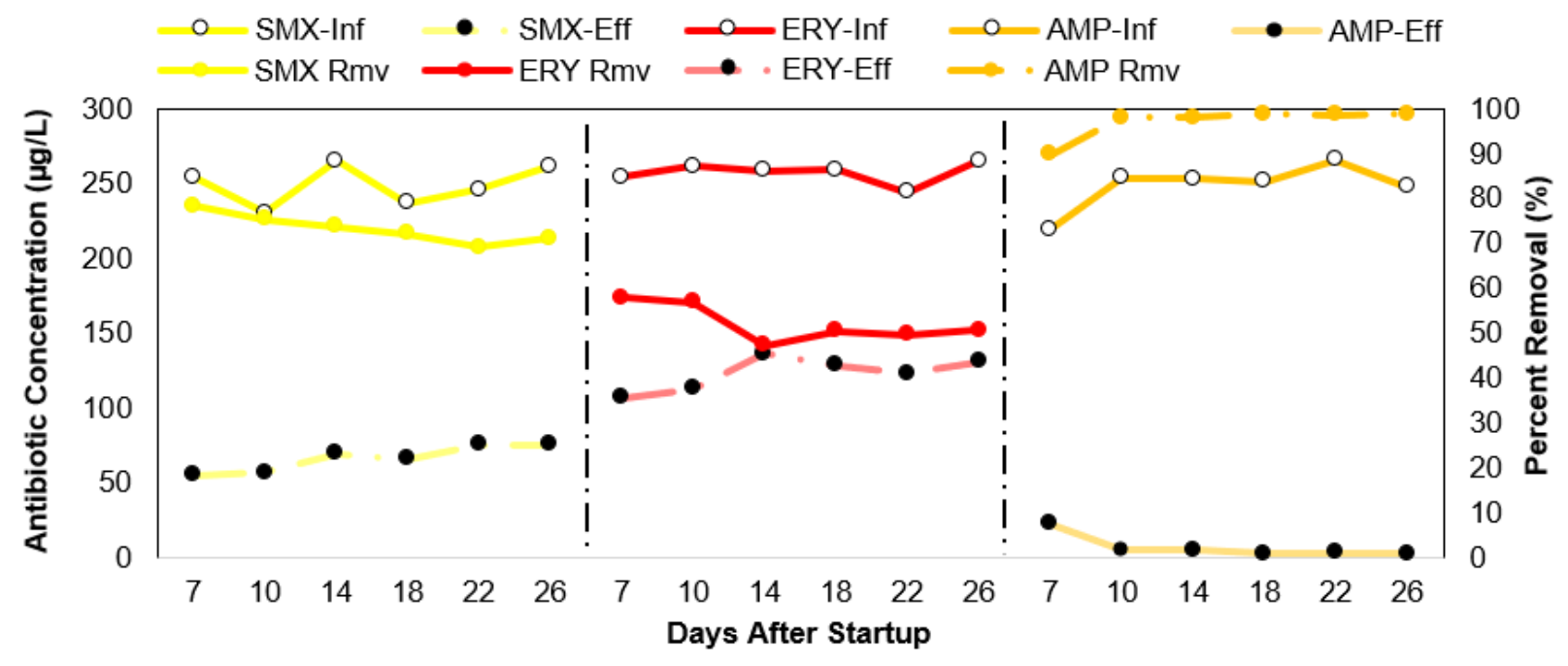

624 Figure 1: Measured antibiotic concentrations in the influent and effluent of AnMBR along

625 with antibiotic removal percentage. Antibiotics (ampicillin, erythromycin, and 626 sulfamethoxazole) were added to influent at a final concentration of $250 \mu \mathrm{g} / \mathrm{L}$ from day 3

627 to day 35.

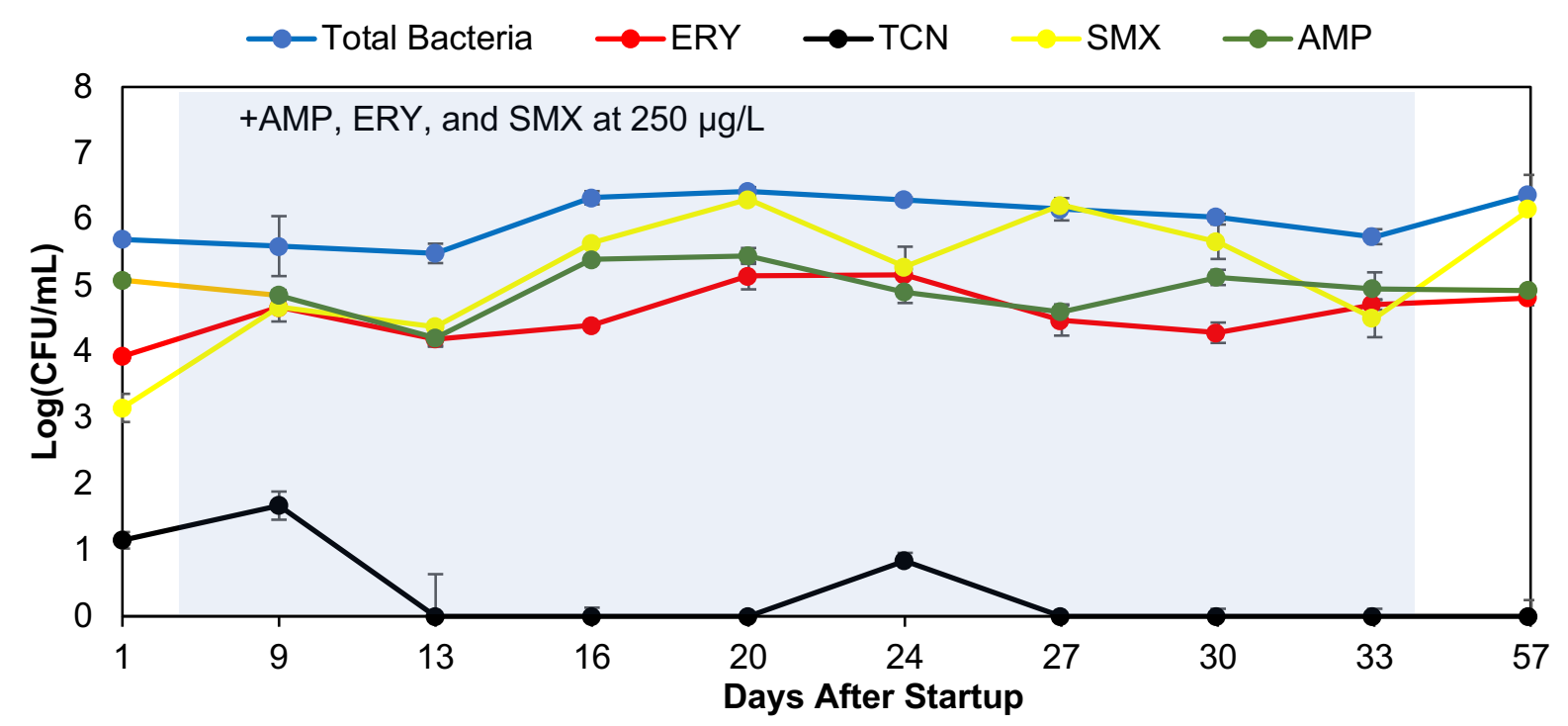

628

629 Figure 2: Heterotrophic plate count for effluent total bacteria, erythromycin resistant 630 bacteria (ERY), tetracycline resistance bacteria (TET), sulfamethoxazole resistant 
631 bacteria (SMX), and ampicillin resistant bacteria (AMP) over the experimental run. All 632 samples were plated in duplicate. The addition of antibiotics lasted from day 3 to day 35.

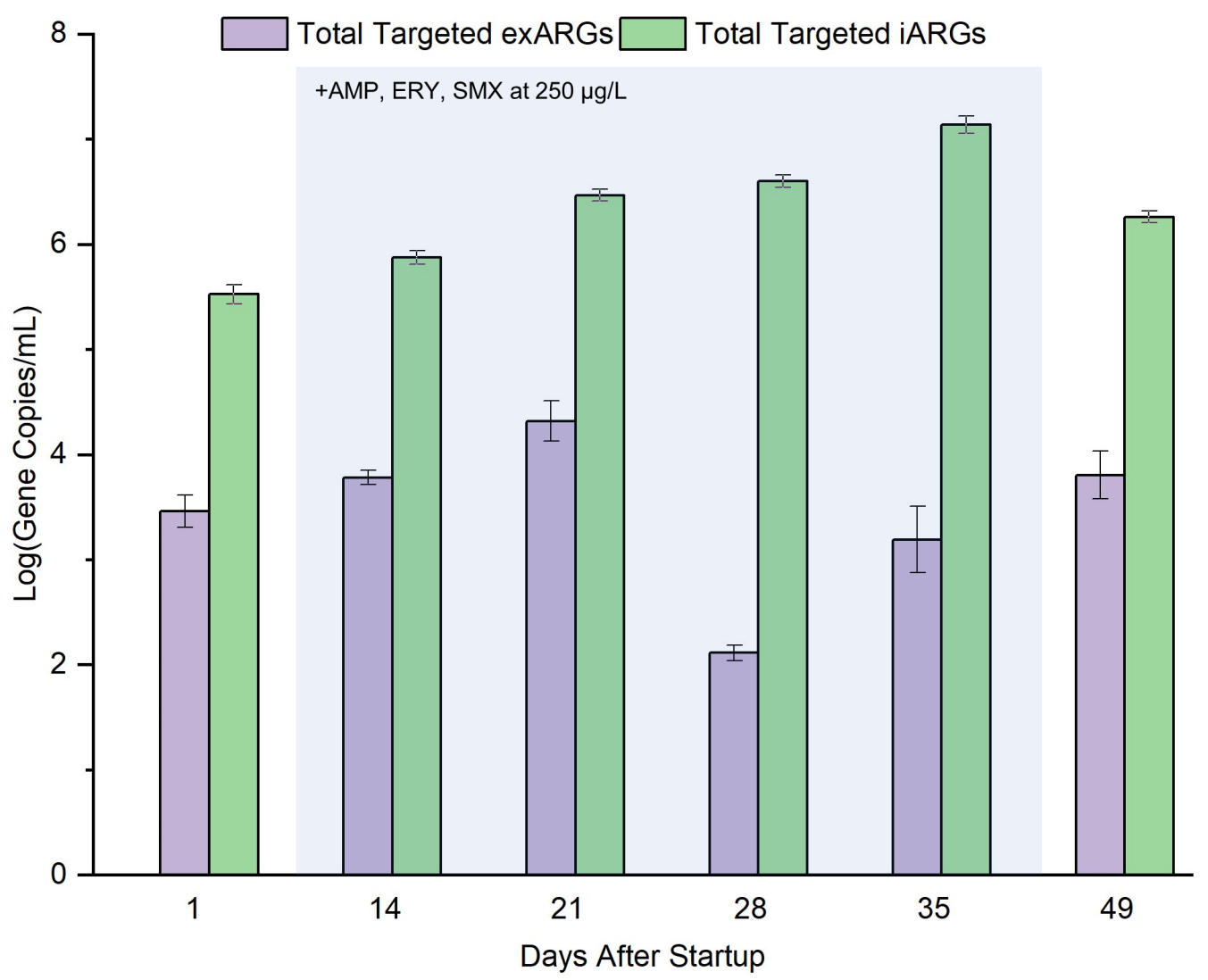

Figure 3: Abundance of total targeted intracellular and extracellular ARGs over the 635 course of the experiment. Targeted ARGs consisting of ampC, ermF, sul1, sul2, tetW, 636 tetO, and oxa-1 were summed for each sampling date and plotted as log(Gene 637 Copies $/ \mathrm{mL}$ ). The mixed antibiotics period lasted from day 3 to day 35 . 


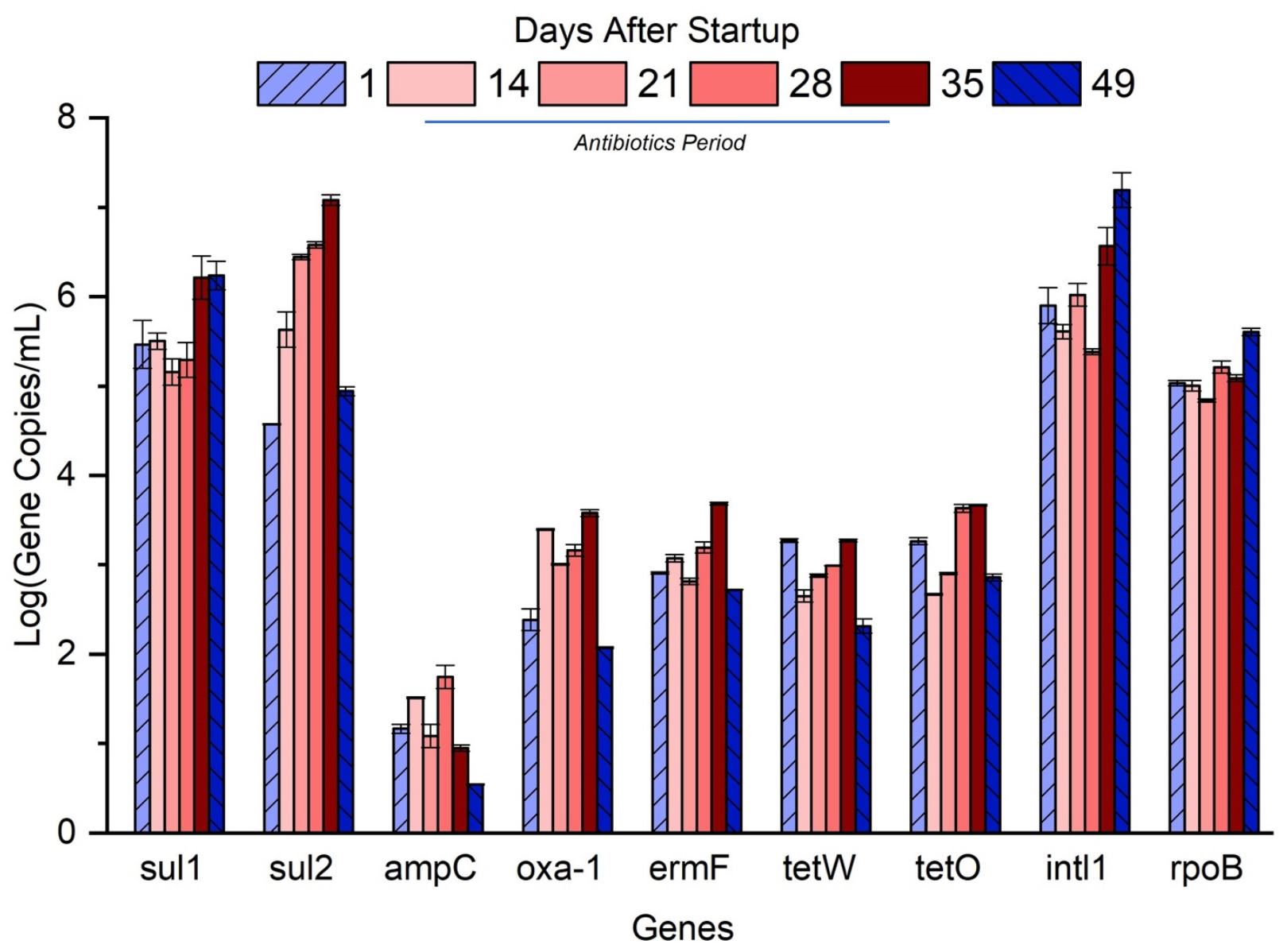

639 Figure 4: Abundance of targeted intracellular ARGs, intl1, and rpoB (Gene Copies $/ \mathrm{mL}$ )

640 in the AnMBR effluent. Error bars represent the mean value and standard deviations of

641 triplicate qPCR runs for each sample. Antibiotics (ampicillin, erythromycin, and

642 sulfamethoxazole) were added to influent at a final concentration of $250 \mu \mathrm{g} / \mathrm{L}$ from day 3

643 to day 35. 


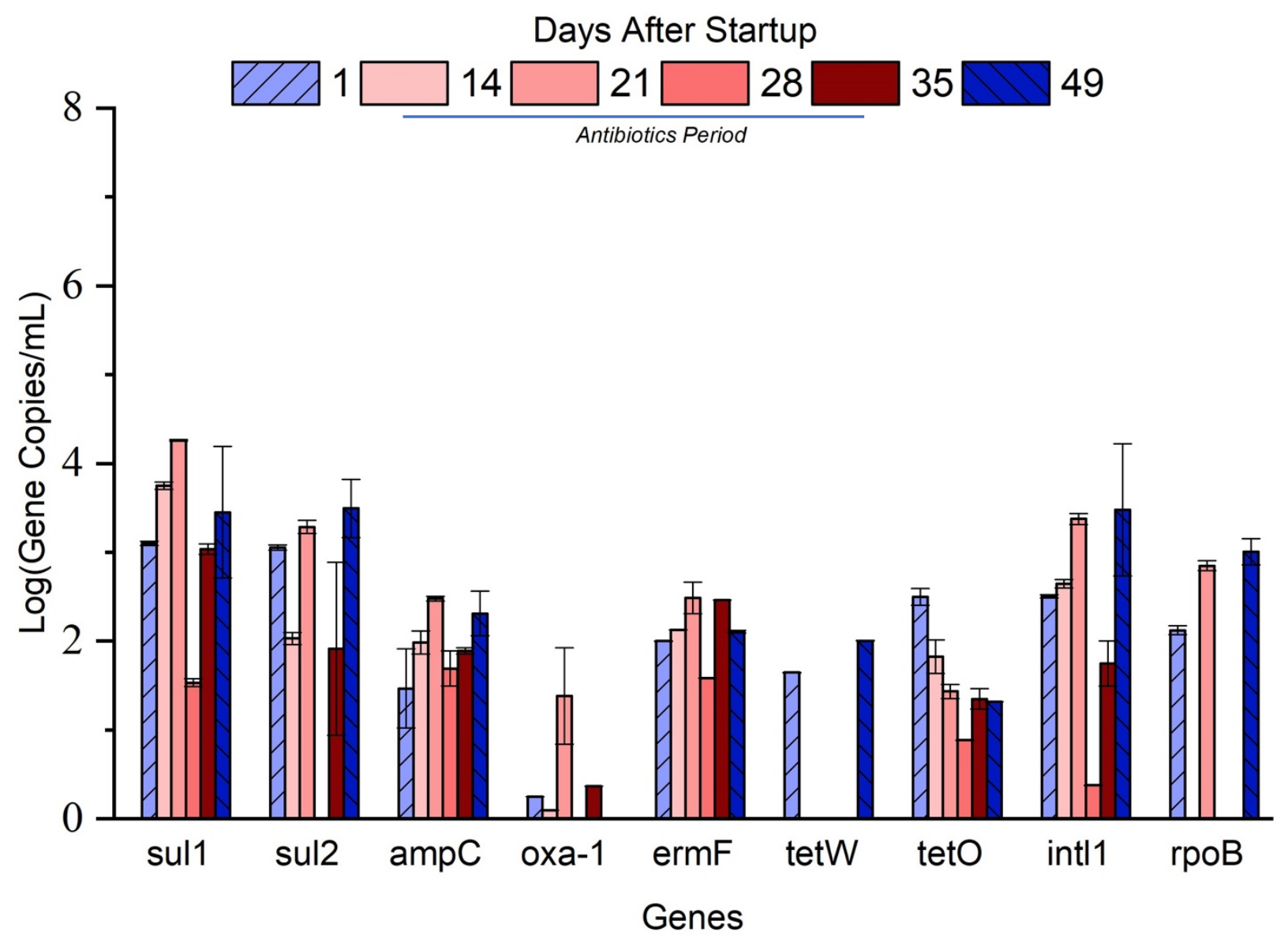

645 Figure 5: Abundance of targeted extracellular ARGs, intl1, and rpoB log(Gene

646 Copies $/ \mathrm{mL}$ ) in the AnMBR effluent during the course of the experimental run. Error bars

647 represent the mean value and standard deviations of triplicate qPCR runs for each

648 sample. Antibiotics (ampicillin, erythromycin, and sulfamethoxazole) were added to

649 influent at a final concentration of $250 \mu \mathrm{g} / \mathrm{L}$ from day 3 to day 35 . Detection limit for each

650 ARG are provided in (SI Table 2)

651

652

653

654

655 
*Astani Department of Civil and Environmental Engineering, University of Southern

664 California, 3620 S Vermont Ave, Los Angeles, CA 90089, USA

667 tCorresponding author (Adam L. Smith)

668 Phone: +1213.740 .0473$

669 Email: smithada@usc.edu

670

671

672

673

674

675

676

677

678

679

680

681

682

683

684

685

686

687

688

689 


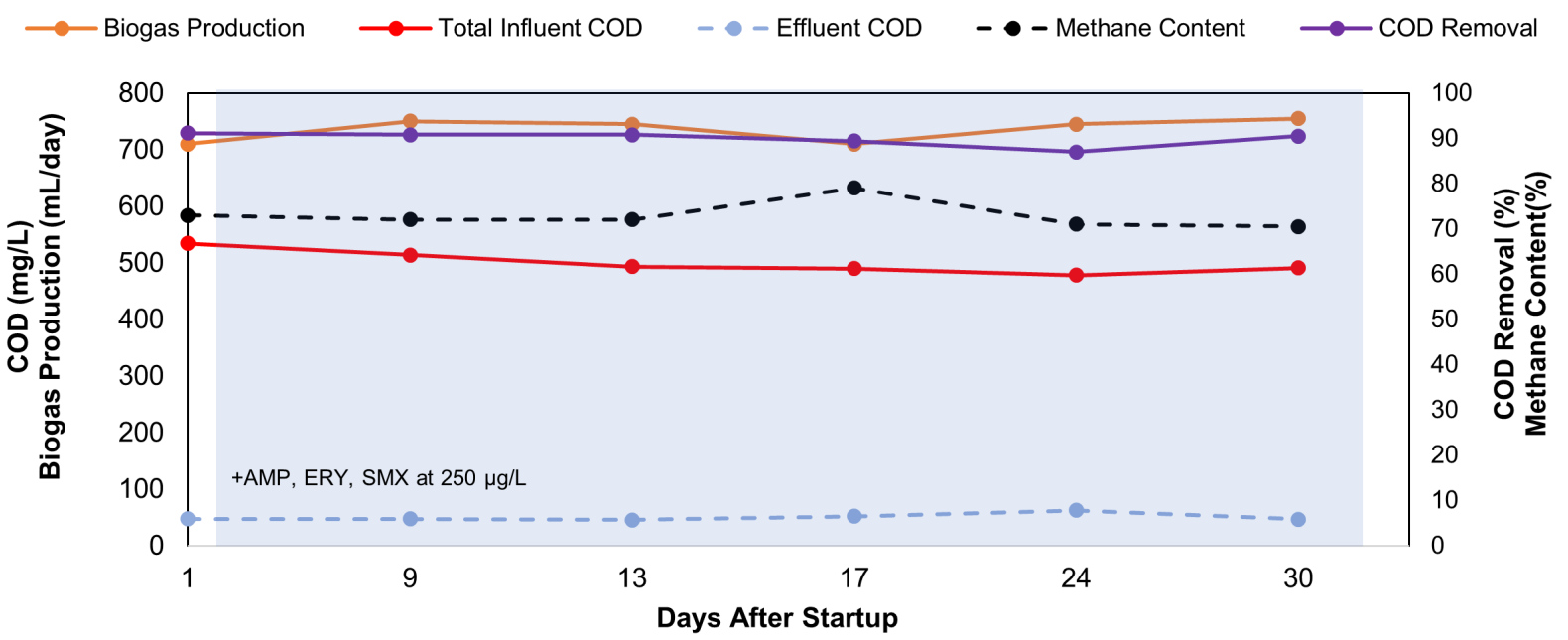

691 SI Figure 1: AnMBR performance for COD removal and biogas production during the 692 addition of antibiotics. Biogas production, total COD and effluent COD concentrations are 693 plotted on the primary y-axis. COD removal and methane content are plotted on the 694 secondary y-axis. Antibiotics (ampicillin, erythromycin, and sulfamethoxazole) were 695 added to influent at a final concentration of $250 \mu \mathrm{g} / \mathrm{L}$ from day 3 to day 35 . 


\section{Bench-scale anaerobic membrane bioreactor operation}

708 The bench-scale AnMBR contained 5 liters of sludge with a MLSS and MLVSS $7.9 \pm 0.4$

$709 \mathrm{~g} / \mathrm{L}$ and $6.1 \pm 0.5 \mathrm{~g} / \mathrm{L}$, respectively. The influent consisted of synthetic wastewater, which

710 was prepared twice a week. The synthetic wastewater contains two components. A

711 concentration solution and a dilution water. The concentrate solution and dilution water

712 were combined at a ratio of $1: 9$ to achieve the final concentration for the feed. Table S1

713 lists the components and final concentration for both solutions.

\begin{tabular}{|c|c|c|c|}
\hline \multicolumn{2}{|c|}{ Concentrate solution } & \multicolumn{2}{|c|}{ Dilution water } \\
\hline Composition & $\begin{array}{l}\text { Concentration } \\
\text { (mg/L) }\end{array}$ & Composition & $\begin{array}{l}\text { Concentration } \\
\text { (mg/L) }\end{array}$ \\
\hline Ammonium Chloride & 11.5 & Sodium Bicarbonate & 369 \\
\hline Calcium Chloride & 11.5 & Magnesium Phosphate & 30.8 \\
\hline Iron Sulfate & 7.7 & Potassium Phosphate & 13.8 \\
\hline Sodium Sulfate & 11.5 & Sodium hydroxide & 18.5 \\
\hline Sodium Acetate & 27 & & \\
\hline Urea & 87 & & \\
\hline Peptone & 11.5 & & \\
\hline Yeast & 46 & & \\
\hline Milk Powder & 115.4 & & \\
\hline Soy Oil & 13.5 & & \\
\hline Hydrochloric acid & 0.2 & & \\
\hline Starch & 115.4 & & \\
\hline Chromium Nitrate & 3.7 & & \\
\hline Copper Chloride & 2.5 & & \\
\hline Manganese Sulfate & 4.9 & & \\
\hline Nickel Sulfate & 1.2 & & \\
\hline Lead Chloride & 0.5 & & \\
\hline Zinc Chloride & 1.2 & & \\
\hline
\end{tabular}

SI Table S1: Synthetic wastewater composition

717 solution overnight. In addition, a peristaltic pump was used to continuously circulate the

$7180.5 \% \mathrm{NaOCl}$ solution through the membranes. To return the permeate back to neutral $\mathrm{pH}$,

719 the membrane modules were pumped with DI water for 3 hours. During the DI water 
720 pumping period, the permeate flux and transmembrane pressure (TMP) results did not

721 indicate any signs of irreversible fouling throughout the experimental run.

723 the production of total biogas. The recirculation of headspace biogas through the sparging

724 tubes underneath the membrane modules (rate $=30 \mathrm{ml} / \mathrm{min}$ ) served to scour the surface

725 of the membranes and prevent membrane fouling. The working volume of the reactor was

726 maintained using an automatic level float switch. Effluent permeate flow was controlled

727 at a rate of 8 min filtration and 2 min backwashing per 10 min period using a peristaltic

728 pump (BT100-1L Multi-channel Peristaltic Pump, Longer, China). Pressure transducers

729 measured the TMP of each membrane module. The permeate flux was set at 7 LMH,

730 which led to hydraulic retention time (HRT) of 16 hours. No sludge was wasted except for

731 sampling, which resulted in a solids retention time (SRT) of 300 days. The software

732 LabVIEW 2014 (Student Edition) was used to monitor and record all relevant AnMBR 733 operational parameters.

734 Chemical oxygen demand (COD) was measured in accordance with USEPA

735 Method 410.4 using a HI801 Spectrophotometer (Hanna Instruments, Woonsocket, RI,

736 USA). Volatile fatty acids (acetate, propionate, formate and valerate), sulfate, phosphate

737 and chloride were measured by ion chromatography on an ICS 2100 (Thermo Fisher

738 Scientific, Waltham, MA) using methods described previously (Chen and Smith, 2018).

739 Headspace biogas samples and effluent were analyzed using a Trace 1310 GC system

740 (Thermo Scientific, NY) with flame ionization detection (FID) as described previously

741 (Chen and Smith, 2018). 


\begin{tabular}{|c|c|c|c|c|c|c|}
\hline Gene & Primers & Preincubation & Amplification & Melting & $\begin{array}{l}\text { Amplification } \\
\text { size (bp) }\end{array}$ & $\begin{array}{c}\text { Detection } \\
\text { limit (gene } \\
\text { copy/mL) }\end{array}$ \\
\hline ermF & $\begin{array}{l}\text { F- CGACACAGCTTTGGTTGAAC } \\
\text { R- GGACCTACCTCATAGACAAG }\end{array}$ & $95^{\circ}$ for $900 \mathrm{~s}$ & $\begin{array}{c}40 \text { cycles, } 95^{\circ} \\
\text { for } 30 \mathrm{~s}, 56^{\circ} \text { for } \\
60 \mathrm{~s}, 70^{\circ} \text { for } 60\end{array}$ & $\begin{array}{c}95^{\circ} \text { for } 10 \mathrm{~s} \\
65^{\circ} \text { for } 60 \mathrm{~s} \\
97^{\circ} \text { for } 1 \mathrm{~s}\end{array}$ & 309 & 350 \\
\hline sul1 & $\begin{array}{c}\text { F- } \\
\text { CGCACCGGAAACATCGCTGCAC } \\
\text { R- } \\
\text { TGAAGTTCCGCCGCAAGGCTCG }\end{array}$ & $95^{\circ}$ for $300 \mathrm{~s}$ & $\begin{array}{c}40 \text { cycles, } 95^{\circ} \\
\text { for } 15 \mathrm{~s}, 58^{\circ} \text { for } \\
30 \mathrm{~s}, 72^{\circ} \text { for } 30 \\
\mathrm{~s}\end{array}$ & $\begin{array}{c}95^{\circ} \text { for } 10 \mathrm{~s} \\
65^{\circ} \text { for } 60 \mathrm{~s} \\
97^{\circ} \text { for } 1 \mathrm{~s}\end{array}$ & 163 & 155 \\
\hline sul2 & $\begin{array}{c}\text { F- } \\
\text { TCCGGTGGAGGCCGGTATCTGG } \\
\text { R- } \\
\text { CGGGAATGCCATCTGCCTTGAG }\end{array}$ & $95^{\circ}$ for $900 \mathrm{~s}$ & $\begin{array}{c}50 \text { cycles, } 95^{\circ} \\
\text { for } 15 \mathrm{~s}, 58^{\circ} \text { for } \\
30 \mathrm{~s}, 72^{\circ} \text { for } 30 \\
\mathrm{~s}\end{array}$ & $\begin{array}{c}95^{\circ} \text { for } 10 \mathrm{~s} \\
65^{\circ} \text { for } 60 \mathrm{~s} \\
97^{\circ} \text { for } 1 \mathrm{~s}\end{array}$ & 191 & 821 \\
\hline intl1 & $\begin{array}{c}\text { F- } \\
\text { CTGGATTTCGATCACGGCACG } \\
\text { R- } \\
\text { ACATGCGTGTAAATCATCGTCG }\end{array}$ & $95^{\circ}$ for $900 \mathrm{~s}$ & $\begin{array}{c}45 \text { cycles, } 95^{\circ} \\
\text { for } 30 \mathrm{~s}, 60^{\circ} \text { for } \\
60 \mathrm{~s}\end{array}$ & $\begin{array}{c}95^{\circ} \text { for } 10 \mathrm{~s} \\
65^{\circ} \text { for } 60 \mathrm{~s} \\
97^{\circ} \text { for } 1 \mathrm{~s}\end{array}$ & 196 & 159 \\
\hline oxa-1 & $\begin{array}{l}\text { F- TATCTACAGCAGCGCCAGTG } \\
\text { R- CGCATCAAATGCCATAAGTG }\end{array}$ & $94^{\circ}$ for $180 \mathrm{~s}$ & $\begin{array}{c}40 \text { cycles, } 94^{\circ} \\
\text { for } 30 \mathrm{~s}, 60^{\circ} \text { for } \\
30 \mathrm{~s}, 72^{\circ} \text { for } 60 \\
\mathrm{~s}\end{array}$ & $\mathrm{~N} / \mathrm{A}$ & 199 & 12100 \\
\hline ampC & $\begin{array}{l}\text { F- CCTCTTGCTCCACATTTGCT } \\
\text { R- ACAACGTTTGCTGTGTGACG }\end{array}$ & $95^{\circ}$ for $300 \mathrm{~s}$ & $\begin{array}{c}45 \text { cycles, } 95^{\circ} \\
\text { for } 45 \mathrm{~s}, 58^{\circ} \text { for } \\
45 \mathrm{~s}, 72^{\circ} \text { for } 60 \\
\mathrm{~s}\end{array}$ & \begin{tabular}{|c|}
$95^{\circ}$ for $10 \mathrm{~s}$ \\
$65^{\circ}$ for $60 \mathrm{~s}$ \\
$97^{\circ}$ for $1 \mathrm{~s}$
\end{tabular} & 189 & 670 \\
\hline tetO & $\begin{array}{l}\text { F- ACGGARAGTTTATTGTATACC } \\
\text { R- TGGCGTATCTATAATGTTGAC }\end{array}$ & $95^{\circ}$ for $600 \mathrm{~s}$ & $\begin{array}{c}40 \text { cycles, } 95^{\circ} \\
\text { for } 15 \mathrm{~s}, 50^{\circ} \text { for } \\
30 \mathrm{~s}, 72^{\circ} \text { for } 30 \\
\mathrm{~s}\end{array}$ & $\begin{array}{c}95^{\circ} \text { for } 10 \mathrm{~s} \\
65^{\circ} \text { for } 60 \mathrm{~s} \\
97^{\circ} \text { for } 1 \mathrm{~s}\end{array}$ & 171 & 2010 \\
\hline tetW & $\begin{array}{c}\text { F- } \\
\text { GAGAGCCTGCTATATGCCAGC } \\
\text { R- } \\
\text { GGGCGTATCCACAATGTTAAC }\end{array}$ & $94^{\circ}$ for $300 \mathrm{~s}$ & $\begin{array}{c}40 \text { cycles, } 94^{\circ} \\
\text { for } 30 \mathrm{~s}, 64^{\circ} \text { for } \\
30 \mathrm{~s}, 72^{\circ} \text { for } 30 \\
\mathrm{~s}\end{array}$ & $\begin{array}{c}95^{\circ} \text { for } 10 \mathrm{~s} \\
65^{\circ} \text { for } 60 \mathrm{~s}, \\
97^{\circ} \text { for } 1 \mathrm{~s}\end{array}$ & 168 & 1030 \\
\hline гров & $\begin{array}{l}\text { F- AACATCGGTTTGATCAAC } \\
\text { R- CGTTGCATGTTGGTACCCAT }\end{array}$ & $95^{\circ}$ for $300 \mathrm{~s}$ & $\begin{array}{c}40 \text { cycles, } 95^{\circ} \\
\text { for } 30 \mathrm{~s}, 55^{\circ} \text { for } \\
30 \mathrm{~s}, 72^{\circ} \text { for } 30 \\
\mathrm{~s}\end{array}$ & $\begin{array}{c}95^{\circ} \text { for } 10 \mathrm{~s}, \\
65^{\circ} \text { for } 60 \mathrm{~s}, \\
97^{\circ} \text { for } 1 \mathrm{~s}\end{array}$ & 381 & 5430 \\
\hline pUC19 & $\begin{array}{c}\text { M13 Forward (F)- } \\
\text { TGTAAAACGACGGCCAGT } \\
\text { L4440 (R)- } \\
\text { AGCGAGTCAGTGAGCGAG }\end{array}$ & $95^{\circ}$ for $300 \mathrm{~s}$ & $\begin{array}{c}40 \text { cycles, } 95^{\circ} \\
\text { for } 30 \mathrm{~s}, 55^{\circ} \text { for } \\
30 \mathrm{~s}, 72^{\circ} \text { for } 30\end{array}$ & $\mid \begin{array}{c}95^{\circ} \text { for } 10 \mathrm{~s} \\
65^{\circ} \text { for } 60 \mathrm{~s}, \\
97^{\circ} \text { for } 1 \mathrm{~s}\end{array}$ & 335 & 550 \\
\hline
\end{tabular}

742 SI Table S2: qPCR thermocycling conditions for all forward and reverse primers used in

743 this study

744

745 Antibiotic quantification 
All glassware used for antibiotic quantification were baked at $400^{\circ} \mathrm{C}$ for a at least one hour and washed with methanol prior to use. Influent and effluent samples (10 $\mathrm{mL})$ and standard solutions were filtered using a $0.2 \mu \mathrm{m}$ PTFE syringe filters (Whatman) and a $10 \mathrm{~mL}$ syringe with Luer lock tip. Prepped samples were preserved in certified $2 \mathrm{~mL}$ amber LC vials (Agilent) and stored at $4{ }^{\circ} \mathrm{C}$ for no more than 3 days prior to analysis.

751 Stock solutions of SMX and ERY were prepared in HPLC-grade methanol at 752 concentrations of $20 \mathrm{mg} / \mathrm{L}$ and stored at $-20^{\circ} \mathrm{C}$. AMP stock solution was prepared in 753 HPLC-grade water at $20 \mathrm{mg} / \mathrm{L}$ because of its insolubility in methanol and stored at $4{ }^{\circ} \mathrm{C}$. 754 Five-point standard calibration curves were generated within the appropriate range for 755 each of the incremental antibiotic influent concentration phases (i.e., 0.1-15 $\mu \mathrm{g} / \mathrm{L}$ for 10 $756 \mu \mathrm{g} / \mathrm{L}, 0.5-70 \mu \mathrm{g} / \mathrm{L}$ for $50 \mu \mathrm{g} / \mathrm{L}$, and $1-300 \mu \mathrm{g} / \mathrm{L}$ for $250 \mu \mathrm{g} / \mathrm{L})$. All calibration curve $\mathrm{R}^{2}$ values 757 were $>99 \%$. Both solvent-based and matrix-matched calibration curves were generated 758 for all three compounds to ensure solvent based standards were representative of influent 759 and effluent concentrations. Specifically, SMX, AMP, and ERY were dissolved in influent 760 and effluent solutions at concentrations of $0.1,1,10,100$, and $1000 \mu \mathrm{g} / \mathrm{L}$ and processed 761 using the same procedure employed to prepare reactor samples described above.

762 Calibration curves of the results were plotted against standard solutions of the same 763 concentrations dissolved in HPLC-grade water. For all three antibiotics, influent and 764 effluent matrices showed equivalent concentrations and scaling at the ranges detected in 765 the HPLC-grade water with $\mathrm{R}^{2}$ values of $>99.9 . \%$. No isotope-labelled internal standards 766 were used because the samples were collected and then analyzed by direct injection LC767 MS on the same (no solid phase extraction required). 

LC gradient program for detection of all three compounds utilized $0.1 \%$ formic acid in water as mobile phase $A$ and acetonitrile as mobile phase $B$ as follows: $t=0.0$ min $A=90 \%$

$771 \quad B=10 \%, t=3.0 \min A=0 \% B=100 \%, t=5.0 \min A=0 \% B=100 \%, t=5.10 \min A=90 \% B=10 \%$.

772 LC conditions used included a flow rate of $0.4 \mathrm{~mL} / \mathrm{min}$, maximum pressure of 600 bar,

773 column temperature of $40^{\circ} \mathrm{C}$, and autosampler tray temperature of $8^{\circ} \mathrm{C}$. A post-column

774 switch was used to divert the first 0.5 min of column elution to waste to avoid sending 775 hydrophilic compounds from the effluent matrix through the MS. Injection volumes ranged 776 from $0.5-10 \mu \mathrm{L}$, depending on the target sample range for each operational phase, to

777 ensure that no compound extracted ion chromatogram peaks exceeded saturation 778 detection values. MS conditions used were as follows: sheath gas temp. of $400^{\circ} \mathrm{C}$, sheath 779 gas flow rate of $12 \mathrm{~L} / \mathrm{min}$, gas temperature of of $225^{\circ} \mathrm{C}$, drying gas flow rate of $5 \mathrm{~L} / \mathrm{min}$, 780 nebulizer pressure of 20 psi, capillary voltage of $3500 \mathrm{~V}$, nozzle voltage of $500 \mathrm{~V}$, 781 acquisition rate of 1.5 spectra/s, and acquisition time of $667 \mathrm{~ms} / \mathrm{spectrum}$. Targeted 782 compound acquisition parameters are provided in Table S2. All compound detection and 783 quantification analyses were performed using the Agilent MassHunter Qualitative 784 Analysis Navigator program.

\begin{tabular}{lcccc}
\hline \multicolumn{1}{c}{ Compound } & $\begin{array}{c}\text { Molecular } \\
\text { Weight (MW) }\end{array}$ & $\begin{array}{c}\text { Retention } \\
\text { Time }(\min )\end{array}$ & $\begin{array}{c}\text { MS } \\
\text { Spectrum } \\
(\mathrm{m} / \mathrm{z})\end{array}$ & $\begin{array}{c}\text { Fragmentor } \\
\text { Voltage }(\mathrm{V})\end{array}$ \\
\hline Sulfamethoxazole & 253.052 & 2.17 & 254.059 & 400 \\
Erythromycin & 733.461 & 2.35 & 734.469 & 100 \\
Ampicillin & 349.110 & 1.44 & 350.117 & 400
\end{tabular}

SI Table S3. Targeted antibiotic properties and MS data acquisition parameters 


\section{Quantification of ARGs using real time qPCR}

All ARG standards used for qPCR quantification were constructed from PCR

793 (Mastercycler nexus, Eppendorf, Hamburg, Germany) amplified products of DNA extracts

794 from activated sludge (listed in Table S2). DNA samples from activated sludge. PCR

795 products were analyzed on $2 \%$ agarose gel electrophoresis to verify the correct amplicon

796 size. The correct DNA bands of interest were purified using Wizard ${ }^{\circledR}$ SV Gel and PCR

797 Clean-Up System (Promega, Madison, WI). Purified amplicons were cloned into

798 linearized pMiniT 2.0 vector and transformed into NEB 10-beta Competent E. coli using

799 the NEB PCR Cloning Kit (New England Biolabs, Ipswich, MA). Trasnformed E. coli were

800 selected for on AMP selection plates. AMP resistant E. coli cells were harvested, and its

801 plasmids was extracted using PureLink ${ }^{\mathrm{TM}}$ Quick Plasmid Miniprep kit (Invitrogen,

802 Carlsbad, CA). Plasmid extracts were sent for Sanger sequencing (Laragen Sequencing

803 \& Genotyping, Culver City, CA) to confirm the presence of target ARG.. DNA

804 concentration of the plasmid extracts were measured using the Quant-iT PicoGreen

805 dsDNA Assay Kit (Invitrogen, Carlsbad, CA). Standard curves were established using 806 serial dilutions of the purified plasmids $\left(10^{-1}\right.$ to $\left.10^{-8}\right)$. For all ARGs, the int/1 gene, and the 807 rpoB gene, qPCR efficiencies ranged from $92 \%$ to $102 \%$. Melting curve and gel 808 electrophoresis were performed to assure the specificity of each qPCR reaction. SI Table 8092 shows the forward and reverse primers, annealing temperatures, and thermal cycling 810 conditions of all ARGs, int/1 and rpoB.. 